\author{
Visión Electrónica \\ Más que un estado sólido \\ https://doi.org/10.14483/issn.2248-4728
}

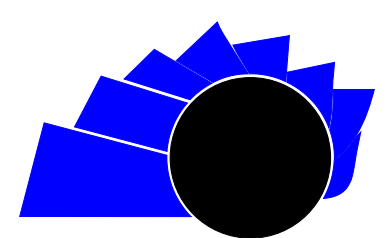

VISIÓN ELECTRÓNICA

A CURRENT VISION

\title{
How exclusion, inequality, curriculum and the teacher's expectations influence the learning of school mathematics
}

\author{
Influencia de la exclusión, la desigualdad, el currículo y las expectativas \\ del maestro en el aprendizaje de las matemáticas escolares
}

Jorge Harvey Rincón-Castillo ${ }^{(1)}{ }^{1}$, Mary Falk de Losada ${ }^{\left(D_{2}\right.}$

INFORMACIÓN DEL ARTÍCULO

Historia del artículo:

Enviado: 02/08/2020

Recibido: 05/08/2020

Aceptado: 03/09/2020

\section{Keywords:}

Equity

Flexibilization of the curriculum

Inclusion

Recreational mathematics

Robust thinking

Teacher expectations

\section{(c)}

Palabras clave:

Equidad

Flexibilización del currículo

Inclusión

Matemática recreativa

Pensamiento robusto

Expectativas de los maestros

\section{ABSTRACT}

This article discusses about the researches that highlighting the importance of inclusion, equity, curriculum flexibility, and teacher expectations for the motivation and academic outcomes from the students. The analysis is based on the literature in which it found the foundations for understanding and describing how these components interrelate and intervene directly in the mathematics learning.

\section{RESUMEN}

En este artículo se analizan investigaciones que destacan la importancia de la inclusión, la equidad, la flexibilización del currículo, y las expectativas de los maestros en la motivación y los resultados académicos de los estudiantes. El análisis se fundamenta en la literatura en la cual se sientan las bases para entender y describir cómo estos componentes se interrelacionan e intervienen en forma directa en el aprendizaje de las matemáticas.

\footnotetext{
${ }^{1}$ MSc. In Mathematical education, Universidad Antonio Nariño, Colombia. Current position, Mathematics Department, Universidad Antonio Nariño, Colombia. E-mail: jorgrincon@uan.edu.co

${ }^{2} \mathrm{PhD}$. in Mathematics, University of Illinois at Chicago, USA. Current position: PhD Director in Mathematics Education, Universidad Antonio Nariño, Colombia. E-mail: director.doctoradoem@uan.edu.co
} 


\section{Introduction}

Many of today's initiatives in mathematical education are aimed at analyzing complexities and proposing actions to achieve inclusive mathematical education based on expectations more positive in front of the possibilities of opening up opportunities for each student to achieve their optimal level in mathematics. These opportunities should focus on opening up new innovation- based learning environments and environments in which the learning barriers are eliminated, introducing greater opportunities to promote inclusion.

The premise in the search to generate these spaces is be able to have dynamic methodologies and strategies that enable the participation of all students. Such spaces must be flexible, open and adaptable to different settings and communities.

With regard to the above the Article 67 of the Political Constitution in Colombia (1991) provides that education is a right of the person and a public service that has a social function, in which the State, society and the family are responsible for the education. It is the work of the State to ensure adequate coverage of the service and to ensure to children the conditions necessary for their access and stay in the educational system. This education is aimed at school-age children and young people, adults, peasants, ethnic groups, people with physical, sensory and psychic limitations, people with exceptional abilities and people who need social rehabilitation. This means ensuring the right of all students to access education regardless of their individual needs.

In contrast to the above are evident more cases of dropout in the figures from the Ministry of National Education due to many factors, including non-inclusive public policies, lack of educational quality, non-challenging and outdated curricula, and other issues that prevent children and young people from completing their studies.

With respect to mathematics there are still cases in which obsolete educational practices and the lack of new and updated didactic methods have contributed to increasing dropouts, these cases have influenced in generalizing an apathy in many students with respect to learning of mathematics.

Additionally based on my experience as a teacher I have observed stigmatizations by some teachers with certain students to whom they classify as good or bad for mathematics, these situations and the lack of expectations and motivation of the teachers themselves have fostered the disinterest of some students who don't see the mathematics as a challenging or useful subject for their academic or work life.

Likewise, it can be argued that the mathematics standards designed by the Ministry of National Education have not been designed to promote inclusion or equity, since they focus on measurable results in standardized tests, leaving behind the achievement and construction of mathematical thinking in students. Also, this situation has contributed to increasing dropout, inequality and exclusion because it doesn't offer access opportunities to education of quality for students, and these standards are not flexible according to the learning rhythms of each person.

\section{Methodology}

Initially, this study analyzes the current panorama of the components mentioned above (inclusion, equity, flexibility of the curriculum, and teachers' expectations), which influence directly the teaching-learning process of mathematics, for which it was taken into account:

\subsection{Methodology applied.}

This analysis was performed through a qualitative and interpretive design of documentary-type on the components of inclusion, equity, flexibility of the curriculum, and teachers' expectations found in several databases.

\subsection{Process.}

A search for studies related to inclusion, equity, flexibility of the curriculum, and teachers' expectations was carried out. Then they were classified to be analyzed by categories and areas of interest in order to justify and define the scope of the research.

2.3. For the analysis of scientific articles its study focused on their activity and impact at international level.

In the activity indicators the current state of science was visualized and within this the number of publications and their productivity were analyzed.

For the impact indicators, the number of citations that the investigations have was taken into account, which gives a characterization of the importance of the 
document and the recognition that the researchers grant to it.

\section{Results and discussion}

\subsection{Regarding inclusion and equity}

Due to the aforementioned it is very important to establish the definition of inclusion and equity in the educational field. For [1], inclusion is an endless process that has to do with the participation of people, the creation of participation systems and their regulations, and the promotion of inclusive values. It is about increasing the participation of all communities in the curriculum and reducing all forms of exclusion and discrimination. Inclusion refers to listening to the voices of the students and acting accordingly to respond to their interests and needs. In the same way the definition of equity in the educational field that best fits to describe the panorama is provided by [2], who bases his definition on three aspects:

1. Respect for other people's ideas, that leads to positive intellectual relationships.

2. Commitment to the learning of others.

3. Learned methods of communication and support.

As mentioned above, one of the supports of education to be achieved is the inclusion and being able to know about the positions of authors widely recognized worldwide in this field allows having a good basis to implement it.

At first point out that there will always be differences in the learning paces of students and that, despite this, currently it continues to seek that the students obtain results with high and fairly homogeneous scores on international tests [3]. Askew points out three aspects to analyze:

1. The curriculum must be designed seeking to meet the needs of the students.

2. Teachers must improve their preparation and expectations levels regarding the academic achievement level of each one of their students and thus favor the inclusion in the educational system.

3. Inclusion and equity must be essential aspects of education and must be applied correctly so that all people have the same rights and opportunities to learn.
On the other hand, in his work promotes inclusion, relational equity and commitment among his students. In one of his experiences, Boaler designed a multidimensional mathematics course for students who had experienced difficulties in previous courses; in this course problem solving and reasoning and argument construction were worked on, always under the premise that all minds are in permanent growth [4].

These new strategies featured a more powerful, fun, and engaging math to the students, impacting them by changing the way they viewed to the math. It is also worth noting that the course was designed under relationships of permanent respect called "relational equity", a term that Boaler uses for all the relationships of respect that were created and strengthened within the members of this course.

For his part, defines inclusion from several dimensions: the participatory social dimension, that means not only being physically present in the classroom but also to be included in mathematical practice; the spatial dimension, basically refers to the amount of time that is spent in the classroom; the social dimension, refers to the ways in which the student participates according to the teacher's teaching method; and the didactic dimension, which is the way in which students engage with practice [5].

The analysis of this article indicates that the interpretation of inclusion by teachers falls short with respect of this important concept in today's school. This observation opens a window of opportunity in terms of achieving true inclusion, seeking to work from the multidimensional concept of inclusion and thus be able to provide the same opportunities for all students that belong to the educational system.

Raises a question about what are the practices that support the diversity of students in math class [6].

The answer of Hobson suggests six concrete practices to promote inclusion and diversity in mathematics, namely:

1. Use the interests of the students with contextualized tasks.

2. Make known the life of some mathematicians, their triumphs and defeats.

3. Design evaluations and tasks with different types of response.

4. Use systematic methods of qualification and participation. 
5. Take into account the logistics of the course.

6. Encourage students to adopt a growth mindset.

Finally, regarding the analysis of the inclusion component, suggests three categories that contribute to changing the development of traditional academic goals (based on "one size fits all") [7], namely:

1. Powerful mathematical minds.

2. Objects that support understanding.

3. Mathematical needs of students with disabilities.

These strategies and resources foster new ways of thinking so that additional resources can be sought, identified, and leveraged to support inclusive practices. Also mentions the work done by Boaler who sets seven standards for a math class [7]:

1. Everyone can learn mathematics at the highest level.

2. Mistakes are valuable.

3. The questions are really important.

4. Math is about creativity and meaning.

5. Mathematics must allow to connect with the real world.

6. Math class is for learning, not for doing.

7. Deepening is more important than speed.

On the other hand, when analyzing Schoenfeld's ideas in his project to build powerful classrooms that focuses on teaching for robust comprehension, it is observed that Boaler's proposal coincides with two of its five dimensions, the dimension of "Access and Equity" and that of "Cognitive Demand". These dimensions suggest to place greater emphasis in the creation of spaces that provides opportunities so that all students have a robust construction of concepts and meanings. They start from the great question of whether within the classroom there is a differentiated access to the content that is being worked on.

All of these reflections on inclusion and equity and ways to promote them are valuable in analyzing the factors that influence in the learning in school mathematics. Now It is considered a second question.

\subsection{How do teacher expectations affect student learning?}

The analysis of this component begins with a phrase by Schoenfeld that says: "The motivation of teachers to use collective argumentation is to encourage students to think and make sense of mathematics".

Initially, carried out a study that works in four categories that they called: Intellectual, quality and belonging, supportive environment in the classroom, and recognition of the difference. The analysis of the study was carried out using Likert-type surveys, one of which showed that the expectations of the students decrease as they progress in their academic process and that in the transition from primary to secondary school, the positive attitude towards mathematics decreases [8].

Four factors were also analyzed: Utilitarian beliefs, traditional beliefs, positive attitude and mathematical anxiety. A survey was conducted in which the following questions were underlined:

Am I good at math? and How do you know you are good at math? The results reflected that older students had responses more negative and highlights responses such as:

- "I am good at math because I do well on tests and assessments"

- $\ddot{\mathrm{I}}$ am good because the teacher tells me so."

- "I am bad because I am in the vegetable class (lowest level class)".

The study also highlights the teacher's influence on the process; the teacher encourages his students to study mathematics with a little more effort to learn and his role is very important in the attitude of the students. This is how teaching can lead a motivated student to continue in an academic world or, on the contrary, frustrate him permanently, leading him to give up the idea of learning mathematics.

In the same way, carried out a dialog between what the teacher expected in terms of doing mathematics in the classroom and the approach that the students expected from their teacher in mathematics classes [9].

The project used collective argumentation, a framework that affords students and teachers to work collaboratively to investigate a problem, question, statement, task, or test. Students participate in enriching discussions in class and discuss their arguments in group 
to exchange and strengthen their ideas.

Suggest for the collective argumentation [9]:

- To carry out videos of the classes in which collective argumentation was used.

- To prepare and collect the problems and homework assigned during each class.

- To know the program and the reference sources (books and texts).

- To observe teacher/student and student/group interactions.

- To make a summary of the explanations and arguments of each working group.

Finally, the study revealed that students became more motivated and confident when working in groups, and that the participation in discussions and argumentation raised interest rates in mathematics. It should be noted that the study is open for possible changes and interpretations in classrooms.

On the other hand, a study carried out by [10] started with a survey in which the participating teachers made known their expectations in the academic performance of their students in reading, to later analyze them at the end of the academic process.

The authors highlight two effects that teachers can produce in their students: (i) The Golem effect that provides adverse and negative effects is the result of the low expectations of teachers that impede the student's good academic performance, and (ii) the Galatea effect which, on the contrary, produces desirable and positive effects is the result of the high expectations of the teachers in the student, an effect that makes possible increases academic performance [11].

There are a large number of individual characteristics that influence the teacher's expectations of his students. According to [10] these include gender, ethnic group, social class, stereotypes, physical attractiveness, language style, student age, personality, and social skills, among others.

The study emphasizes the low expectations of teachers mainly with respect to ethnic minority groups; it is evident (in the United States) that teachers have better expectations in the white ethnic group. This appreciation increases the gap in terms of achieving equity and inclusion in the educational system.
This study evidences a phenomenon quite harmful for students and it is the academic exclusion practiced according to damaging expectations by some teachers who have forgotten their true work in education.

Regarding the national scope, there is no literature that reflects research on this phenomenon, so the initial question of this section: How do teachers' expectations affect student learning? It is proposed as an open question for possible researches orienting it towards a possible scenario of public schools vs. private schools.

\subsection{Regarding the flexibility of the curriculum}

This component seeks to analyze the most relevant aspects of the curricula and determine if the design is based on inclusion and on the current needs of the students.

Initially, indicates that educational policies in United States that implement curricula hinder the advancement of teaching and learning mathematics [12]; for this reason, he invites teachers to create one and fight to leave behind the TSM (Textbook School Mathematics), because education is a dynamic process and as such requires continuous changes contextualized with the reality of students.

From the national level, Robayo carry out a curricular analysis from sociopolitical perspectives [13] and cite to [14] who affirm that "a model imposed from above closes the possibilities for the people involved in the development of the real curriculum takes ownerships of the process".

Now from a critical and reflective perspective on how mathematics is used in real life, [13] that the curriculum is not prescriptive as it does not intend to homogenize; it is organized according to the social, cultural and personal circumstances of the students. However, it is important to consider who and how organized the curriculum, so they recommend the suggestions of Valero [14], who propose that it be the community that forms part of school mathematical practices who makes the curricular decisions, because teachers, students, parents and managers have an active role in the design and implementation of the curriculum. In this way, both the assumptions and the same life of the curriculum are democratic and respond to the social, cultural and political situations of those who directly intervene in it.

On the other hand, present considerations of the curriculum in some of the countries with better results 
in PISA and TIMSS international studies of the last years (Japan, Korea and Singapore) [15]. The study program for the three countries is the core of education, which implies that a very complete work is carried out in curricula and study plans.

These countries base their work on four factors to carry out their curricula and study programs.

a) Policies on mathematics curriculum, also called the "What?"

b) Agents engaged in policy making, also called the "Who?"

c) Factors influencing the policy design of mathematics programs within a particular environment

d) Future instructions on math program policy

It is worth mentioning, according to [15], that these excellent results in international tests are not a coincidence; strong work is being done on the study plans which are periodically reviewedwith officials from the respective ministries and classroom teachers. These periodic reviews are made as a negotiation in which all allege their suggestions and exchange ideas.

Now it is important to point out the contribution to inclusion that the flexibility of the curriculum can make. As indicated by [16] flexibility has been taken into account in many curricular reform documents in the last two decades, as well as in many innovative curricula, textbooks, software and others. Mention is also made in the literature of the belief that flexibility enables viable strategies for the younger and weaker in mathematics, nonetheless the research and analysis on this aspect are very scarce.

To end this analysis of the curriculum, [3] suggests conducting an analysis of the different ways of thinking about the design of a curriculum and thus achieving more productive and effective positions that may have practical implications in a more inclusive and equitable mathematics education.

For all of the above, it can be said that the initial problem of this article directly affects the learning process of school mathematics and that this learning process of mathematics requires a change that provides a better academic environment for inclusion and fairness, holding firmly to the conviction that the main practical objective of mathematics education should be to develop the student's mathematical thinking [17] and to stimulate his creativity, confronting him with situations that foster the solution of imaginative problems and from his context where we notice especially that recreational mathematics can play a vital role in achieving this goal.

Finally, promoted five components that must be achieved in the mathematics classroom to accomplish these goals [18]. These components are related and briefly described from the student's point of view:

1. The content. What is the main idea in this lesson? How does it connect with what I already know?

2. Cognitive demand. How much time do they give me to think and build meaning (make sense) of things? What happens when I get stuck? Do they invite me to explain things or just to give answers?

3. Access and equity. Do they let me participate in the meaningful learning of math? Can I hide or not be taken into account? In what ways do they keep me engaged (or conquered)?

4. Agency, authority and equity. What opportunities do I have to explain my ideas? How does it continue to build on my contributions? How do they recognize me as someone capable and skillful of making contributions?

5. Formative evaluation. How are my thoughts (ideas) included in classroom discussions? The instruction responds to my ideas and helps me to think more deeply.

\section{Conclusions}

In the previous paragraphs, a review and analysis of some of the researches related to inclusion in the mathematics classroom and possible ways of promoting it have been carried out.

Regarding inclusion and equity, based on evidence from various expert authors on this research topic, it can be seen that when pedagogical practices designed based on the needs of students are developed and relationships of interpersonal respect are strengthened, students become feel more motivated in a way that increases their willingness to learn mathematics.

Concerning to the curriculum and according to the literature of several researchers working on this aspect, innovations are needed to have a challenging and innovative curriculum designed based on the needs of the population and its context. This design can be achieved through joint work between the corresponding government entities and the educational community where the curriculum will be implemented, however the 
inclusive flexibilization of the curriculum within each classroom can also be achieved at the initiative of each teacher.

It is important to emphasize that problem solving can help develop more robust thinking in students in such a way that when a student is mentally challenged and has had access to the tools required, he develops their creativity and imagination and strengthens the meaning that he constructs for mathematical concepts that were previously abstract and possibly even arbitrary for him.

Motivational processes affect how students can bring to light and enhance their skills and knowledge and the ways to apply them to solving everyday problems.

Teacher's positive expectations in front of all students despite the variety in their personal strengths, with possibilities for each to show their own strategies, develop their preferred learning style, and build their own robust understanding is possible through the developing of a flexible curriculum coupled with careful preparation of motivating learning experiences.

The introduction of a new concept through activities that intellectually challenge students generates robust learning of the concept that wants to introduce; Additionally, recreational math activities in addition to intellectually challenging students are a factor that allows all students to be included, favoring their creativity and imagination.

\section{References}

[1] T. Booth, M Ainscow, "Guía para la educación inclusiva: desarrollando el aprendizaje y la participación en los centros escolares, 2015. [Online]. Available at: https://www.oei.es/historico/ IndexLibroAgosto.pdf

[2] J. Boaler, "Promoting relational equity and high mathematics achievement through an innovative mixed-ability approach", British Educational Research Journal, vol. 34, no. 2, pp. 167-194, 2013. https://doi.org/10.1080/01411920701532145

[3] M. Askew, "Diversity, inclusion and equity in mathematics classrooms: From individual problems to collective possibility", Diversity in mathematics education, pp. 129-145, 2014. https://doi.org/10. 1007/978-3-319-05978-5_8

[4] J. Boaler, "Designing mathematics classes to promote equity and engagement", Journal of Mathematical
Behavior, vol. 41, pp. 172-178, 2016. https://doi. org $/ 10.1016 / j \cdot j$ jmathb. 2015.01.002

[5] H. Roos, "Developing Inclusion in Mathematics: The Impact of the Principal", Nordic Research network on Special Needs Education in Mathematics (NORSMA 7), pp. 14- 15, 2013.

[6] N. L. Hobson, "Six Ways Mathematics Instructors Can Support Diversity and Inclusion", 2017. [Online]. Available at: https: //blogs.ams.org/matheducation/2017/03/06/ six-ways-mathematics-instructors-can-support -diversity-and-inclusion/

[7] P. Tan, "Advancing Inclusive Mathematics Education: Strategies and Resources for Effective IEP Practices", International Journal of Whole Schooling, vol. 13, no. 3, pp. 28-38, 2017.

[8] P. Grootenboer, M. Marshman, "Changes in Affective Responses to Mathematics Through the Middle School Years", Mathematics, Affect and Learning, pp. 91-110, 2015. https://doi.org/10. 1007/978-981-287-679-9_6

[9] M. Marshman, R. Brown, "Coming to Know and Do Mathematics with Disengaged Students", Mathematics Teacher Education and Development, vol. 16, no. 2, pp. 71- 88, 2014.

[10] C. Rubie-Davies, J. Hattie, R. Hamilton, "Expecting the best for students: Teacher expectations and academic outcomes", British Journal of Educational Psychology, vol. 76, no. 3, pp. 429-444, 2010. https://doi.org/10.1348/ $000709905 \times 53589$

[11] N. Balacheff, "A study of students' proving processes at the junior high school level", 1988. [Online]. Available at: https://hal. archives-ouvertes.fr/hal-01652045/document

[12] H. H. Wu, "Potential impact of the common core mathematics standards on the American curriculum", Mathematics curriculum in school education, pp. 119-142, 2014. https://doi.org/10. 1007/978-94-007-7560-2_7

[13] B. J. Robayo, J. Duarte, "La responsabilidad del currículo de matemáticas en la formación de ciudadanos que cuestionen la estructura social de clases", Revista Colombiana de Educación, no. 73, pp. 299-322, 2017. https://doi.org/10.17227/ 01203916.73 rce299.322

[14] E. J. Barbeau, P. J. Taylor, "ICMI study 16: Challenging mathematics in and beyond the 
classroom: Discussion document", Educational studies in mathematics, vol. 60, no. 1, pp. 125-139, 2005. https://doi.org/10.1007/ s10649-005-8481-7

[15] K. Y. Wong, M. Koyama, K. H. Lee, "Mathematics curriculum policies: a framework with case studies from Japan, Korea, and Singapore", Mathematics curriculum in school education, pp. 79-91, 2014. https://doi.org/10.1007/978-94-007-7560-2_5

[16] L. Verschaffel, J. Torbeyns, B. Smedt, K. Luwel, W. Van Dooren, "Strategy flexibility in children with low achievement in mathematics", Educational and Child Psychology, vol. 24, no. 2, pp. 16-27, 2007.

[17] A. Schoenfeld, "Learning to think mathematically: Problem solving, metacognition, and sense-making in mathematics", Journal of education, vol. 96, no. 2, pp. 1-38, 2016. https://doi.org/10.1177\% 2F002205741619600202

[18] A. H. Schoenfeld, "An Introduction to the Teaching for Robust Understanding (TRU) Framework", 2016. [Online]. Available at: https: //truframework.org/wp-content/uploads/2018/ 03/Introduction-to-TRU-2018-version.pdf 